\title{
Postoperative Outcome of Caesarean Section in Closure Versus Nonclosure of Parietal Peritoneum
}

\author{
${ }^{1}$ Avantika Sharma, ${ }^{2}$ Nupur Hooja, ${ }^{3}$ Apoorv Shastri, ${ }^{4}$ Rajani Nawal, ${ }^{5}$ Smriti Bhargava, ${ }^{6}$ Manisha Kala, \\ ${ }^{7}$ Bhomraj Kumawat, ${ }^{8}$ Richa Manish
}

\section{ABSTRACT}

Aim: Caesarean section is the commonest obstetric surgery. Any change in the operative technique however small, affects the postoperative outcome.Effect of nonclosure of peritoneum on postoperative outcome was evaluated.

Method: This was an interventional study. Postoperative condition of the women was assessed after caesarean section. Peritoneum was either closed or left open and outcome was compared.Statistical analysis was done.

Results: Most women in the nonclosure group had earlier ambulation and return of bowel activity and breastfed early in comparison to the closure group. More postoperative pain, nausea and vomiting was observed when peritoneum was closed. Since the stay in hospital was less in women with peritoneal nonclosure and because of use of lesser suture material, this was more cost effective too.

Conclusion: Leaving the peritoneal open was a better method than closing it because patient was more comfortable, there was lesser morbidity and shorter hospital stay and cost effectiveness.

Clinical significance: The policy of peritoneal nonclosure will help in decreasing maternal discomfort, shorter hospital stay and overall economical.

Keywords: Caesarean, Closure, Nonclosure, Peritoneum.

How to cite this article: Sharma A, Hooja N, Shastri A, Nawal R, Bhargava S, Kala M, Kumawat B, Manish R. Postoperative Outcome of Caesarean Section in Closure Versus Nonclosure of Parietal Peritoneum. J South Asian Feder Obst Gynae 2018;10(3):182-185.

Source of support: Nil

Conflict of interest: None

Date of received: $5 / 3 / 2017$

Date of acceptance: 13/12/2017

Date of publication: December 2018

\footnotetext{
${ }^{1,3}$ Senior Registrar, ${ }^{2}$ Professor, ${ }^{4,5}$ Assistant Professor, ${ }^{6-8}$ Resident ${ }^{1,2,4-8}$ Department of Gynaecology and Obstetrics, Sawai Man Singh Medical College, Jaipur, Rajasthan, India

${ }^{3}$ Department of Surgery, Sawai Man Singh Medical College, Jaipur, Rajasthan, India

Corresponding Author: Nupur Hooja, Professor, Department of Gynaecology and Obstetrics, Sawai Man Singh Medical College, Jaipur, Rajasthan, India, e-mail: hoojasjaipur@gmail.com
}

\section{INTRODUCTION}

Caesarean section is the commonest surgery in obstetrics. There has been a steady increase in the caesarean section rate globally. ${ }^{1}$ Efforts of researchers are directed towards finding a safe, quick technique with good postoperative outcome, short hospital stay as well as being cost-effective.

Various studies have been done with changes in the technique of caesarean section. However, there are very few studies to see if a small step like closure of peritoneum could be omitted and its effect has on the postoperative status of the mother. With an improved outcome, it would be easier for her to breastfeed the baby and be involved in the care of the new-born. It would also lead to a decrease in the time of surgery and suture used.

Hence the present study was undertaken with the objective of finding an association between peritoneum closing technique and postoperative outcomes like postoperative pain score, nausea and vomiting, return of bowel sounds, ambulation and breast feeding. Incidence of fever and duration of hospital stay was also compared.

\section{METHOD}

This was a interventional study conducted over one year. Institutional Review Board Clearance and Ethical committee approval were taken prior to the study. For minimum detectable difference in mean visual analog scale (VAS) for pain of one, 40 women were selected in each group.

Primigravidae with live singleton term pregnancy, in reproductive age group undergoing caesarean section and willing to be included in the study were chosen.

Woman with polyhydramnios, severe anaemia, any sign of sepsis, hypertensive disease of pregnancy, active cardiac, renal, pulmonary or hepatic disease any neurological disorder were not included.

In both the groups, abdomen was opened by Joel Cohen technique. The caesarean section was done in a similar manner in all except that parietal peritoneum was sutured or left open according to the group allocation. Postoperative pain assessment was done using visual analog scale (VAS). Presence of nausea, vomiting, timing of ambulation and breast feeding, return of bowel sounds 
and fever if any in the postoperative period was noted. Duration of hospital stay was also compared in the two groups. Data collected were statistically analysed. A p-value $<0.05$ was taken as significant.

\section{RESULTS}

There were 40 women in both group. In a group, peritoneum was closed while in group B, it was left open. Body mass index (BMI), age of women and the duration of pregnancy were similar in two groups (Table 1).

The average time for the surgery was less when the peritoneum was left open (Table 2).

The postoperative pain score was less as noted by VAS after 24 hours when the peritoneum was left than when closed. This difference was highly significant. Nausea, vomiting and febrile episodes were also less when the peritoneum was not closed (Table 3 ).

Time of first breastfeed, return of bowel sounds and ambulation was earlier in women with nonclosure of peritoneum. Women stayed in hospital for lesser time when the peritoneum was left open (Table 4).

\section{DISCUSSION}

During the caesarean, the peritoneum is opened before the uterus is incised. Both visceral and parietal peritoneum are usually closed in abdominal surgeries. Maternal comfort and wound condition if the peritoneum was closed or not at caesarean section was evaluated in the study.

In our study, the mean duration of surgery was $29.1 \pm$ 2.37 min when parietal peritoneum was left open and was significantly less than the closure group. They decrease in surgical time decreased the risks of anaesthesia. ${ }^{2,3}$ Sarwat et al. also had less operating time in non-closure group and suggested that this decreased the risk of anaesthetic complications, wound infection and thromboembolic complications. ${ }^{4}$ It also led to decrease in cost by better and efficient use of operation rooms. However, in the CAESAR study $^{5}$ and CORONIS Trial, ${ }^{6}$ they found no differences in duration of caesarean section in the two groups.

The pain score as noted by VAS scale difference between peritoneal closure and nonclosure group taken at 24 hours postoperatively was highly significant. The

Table 1: Patient characteristics

\begin{tabular}{llll}
\hline Patient characteristics & Group A (closure) $n=40$ & Group B (nonclosure) $n=40$ & Statistical significance \\
\hline Mean age (In years + S.D.) & $23.27 \pm 3.24$ & $22.90 \pm 2.79$ & $\mathrm{p}=0.587$ Not significant \\
Gestational age $($ In weeks + S.D.) & $38.82 \pm 1.62$ & $38.24 \pm 2.080$ & $\mathrm{p}=0.542$ Not significant \\
Body mass index $\left(\mathrm{kg} / \mathrm{m}^{2}\right)$ & $21.37+1.34$ & $21.56+1.544$ & $\mathrm{p}=0.558$ Not significant \\
\hline
\end{tabular}

Table 2: Comparison of duration of surgery in the study groups

\begin{tabular}{llll}
\hline Duration of surgery (In minutes) & Group A $n=40$ & Group B $n=40$ & Statistical significance \\
\hline & $31.475+2.286$ & $29.1 \pm 2.37$ & $\begin{array}{l}p=0.00003 \text { Highly } \\
\text { significant }\end{array}$ \\
\hline
\end{tabular}

Table 3: Comparison of postoperative condition of the women

\begin{tabular}{llll}
\hline & $\begin{array}{l}\text { Group A } \\
n=40\end{array}$ & $\begin{array}{l}\text { Group B } \\
n=40\end{array}$ & Statistical significance \\
\hline $\begin{array}{l}\text { Meantoperative condition } \\
\text { postoperatively }\end{array}$ & $4.13 \pm 0.33$ & $\begin{array}{l}p=0.00001 \\
\text { Highly significant }\end{array}$ \\
$\begin{array}{l}\text { Nausea and vomiting } \\
\text { Fever }\end{array}$ & $7(17.5 \%)$ & $1(2.5 \%$ & $p=0.001$ significant \\
& $7(17.5 \%)$ & $1(2.5 \%)$ & $p=0.001$ significant \\
\hline
\end{tabular}

Table 4: Comparision of postoperative outcome in the study groups

\begin{tabular}{|c|c|c|c|}
\hline Postoperative patient outcome & $\begin{array}{l}\text { Group A } \\
\mathrm{n}=40\end{array}$ & $\begin{array}{l}\text { Group B } \\
n=40\end{array}$ & Statistical significance \\
\hline $\begin{array}{l}\text { Timing of first breastfeeding } \\
\text { (hours) }\end{array}$ & $4.78 \pm 0.80$ & $2.77 \pm 0.61$ & $\begin{array}{l}p=0.00003 \\
\text { Highly significant }\end{array}$ \\
\hline $\begin{array}{l}\text { Timing of return of bowel sound } \\
\text { (hours) }\end{array}$ & $8.08 \pm 1.54$ & $4.975 \pm 2.72$ & $\begin{array}{l}p=0.003 \\
\text { significant }\end{array}$ \\
\hline Timing of ambulation (hours) & $31.50 \pm 7.41$ & $13.6 \pm 4.86$ & $\begin{array}{l}p=0.00001 \\
\text { Highly significant }\end{array}$ \\
\hline Duration of hospital stay (days) & $5.50 \pm 2.29$ & $4.125 \pm 0.51$ & $\begin{array}{l}p=0.00003 \\
\text { Highly significant }\end{array}$ \\
\hline
\end{tabular}


women in the closure group had higher pain score as compared to the nonclosure group. The epithelial lining of peritoneum is very sensitive and responds by releasing cytokines and interleukin which cause pain. On suturing the peritoneum, foreign body reaction is caused which results in peritoneal inflammation and causes pain. Postoperative pain could be due to blood clots in the space under the uterovesical fold when the peritoneum is closed. ${ }^{7}$ Kurek Eken et al. also found pain to be significantly more in closure groups than nonclosure groups. ${ }^{8}$ In the CORONIS trial however; postoperative pain was same in both. ${ }^{6}$

In our study, we also found significantly less postoperative nausea and vomiting in the nonclosure group. Since non-closure of the peritoneum during caesarean section reduces the duration of the procedure, less operative time reduced the duration of exposure to anaesthesia and that of exposure of wound to external environmental contaminants that may reflect as decrease in the incidence of febrile episodes.$^{9}$ Noreen et al. found significant lower febrile and infectious morbidity in nonclosure group and it was highly significant. ${ }^{4}$

The mean timing of first breast feeding in our study in the nonclosure group was $2.77+0.61966$ hours which was significantly less than the closure group. Postoperative pain can lead to delayed breast feeding. This may cause breast engorgement and may also prolong the hospital stay. Decrease in post-operative pain improves mother's comfort and affects her bonding with the neonate. ${ }^{10}$

In our study, the mean time of return of bowel sound in the nonclosure group was $4.975+2.72$ hours and it was significantly less than the closure group. Postoperative pain can lead to unpleasant physiologic responses which could lead to paralytic ileus and increased usage of analgesics. ${ }^{10}$ Less duration of peritoneal cavity exposure intra-operatively in the nonclosure groups and less bowel handling could be the reason for earlier return of bowel sounds. ${ }^{11}$ Agarwal et al. also observed in their study that closure group had more distension and took longer time to regain intestinal motility. ${ }^{9}$

In our study, the mean time of ambulation in the nonclosure group was $13.6 \pm 4.86$ hours and it was significantly less than the closure group. It has been suggested that lesser bowel handling and lesser operating time results in early appearance of bowel sounds, allowing early oral intake. This results in earlier ambulation. ${ }^{12}$ Rokade et al. also found statistically significant difference in the mobilization time of the women in the two different groups. ${ }^{13}$

The average duration of hospital stay in our study was $4.125 \pm 0.515$ days when peritoneum was left open, this was significantly less than the closure group with $p$ value of 0.00003 .

Early oral intake and ambulation, lesser pain and febrile morbidity resulted in a sense of general well being to the patient and their earlier discharge from the hospital. Noreen Sarwat also found reduced hospital stay in the nonclosure group. ${ }^{4}$ In the CORONIS trial no acceptable difference was seen in duration of hospital stay in the two groups. ${ }^{6}$

\section{CONCLUSION}

From these observations, we can conclude that parietal peritoneum in caesarean section should be left open unless otherwise indicated. It results in less postoperative morbidity like pain, nausea, vomiting and fever and earlier breast feeding, ambulation, faster return of bowel activity. Shorter duration of hospital stay, less requirement of suture material and analgesics makes it more cost effective.

\section{LIMITATIONS OF THE STUDY}

The study was done in a small group in a tertiary care hospital. There is a need to adopt and spread the message of leaving the peritoneum open at caesarean section.

\section{CLINICAL SIGNIFICANCE}

Adopting the policy of peritoneal nonclosure will help in decreasing maternal discomfort, shorter hospital stay and be overall economical.

\section{REFERENCES}

1. Arias F, Bhide AG, Arulkumaran S, Damania K, Daftary SN, editors. Practical guide to high risk pregnancy and delivery. Elsevier health sciences; 2012 May 14.

2. Deshpande H, Burute SB, Madkar CS, Dahiya P. The effect of suturing and nonsuturing of visceral and parietal peritoneum on postoperative pain in caesarean section.Int. Journal of Pharmacy and Biomedical Science 2012;3(4):164-166.

3. Tabasi Z, Mahdian M, Abedzadeh-Kalahroudi M. Closure or non-closure of peritoneum in cesarean section: outcomes of short-term complications. Archives of trauma research. 2013;1(4):176.

4. Noreen S, Alam M, Khan WY, Sultana R, Gul S. A comparison of peritoneal closure with non-closure for short term morbidity in emergency lower segment cesarean section KJMS. January-April. 2015;8(1):76-79.

5. Brocklehurst P, Quigley M, Ayers S, Juszczak E. Caesarean section surgical techniques: a randomised factorial trial (CAESAR). BJOG-Int J Obstet Gy. 2010;117(11):13661376.

6. Group TC. Caesarean section surgical techniques (CORONIS): a fractional, factorial, unmasked, randomised controlled trial. The Lancet. 2013 Jul 26;382(9888):234-248. 
7. Fahmy MM, Saleh SA, Khouly NIE, Zahrane RA. Short- term effect of closure versus non-closure of peritoneum at cesarean section .Life Science Journal 2015;12(2)60-63.

8. Kurek Eken M, Özkaya E, Tarhan T, İçöz Ş, Eroğlu Ş, Kahraman ŞT, Karateke A. Effects of closure versus non-closure of the visceral and parietal peritoneum at cesarean section: does it have any effect on postoperative vital signs? A prospective randomized study. The Journal of Maternal-Fetal \& Neonatal Medicine. 2016 Sep Sep 5;30(8):922-926

9. Agarwal DN, Agarwal DB. Effect of Non Closure of Peritoneum on Outcome of Caesarean Section-A Prospective Randomised Control Study. International Journal of Scientific Research. 2016 Aug 1;4(6).

10. Cheema H K, Singh C, Mehta S S, Suri S. Closure versus Nonclosure of peritoneum in cesarean section and evaluation of post-operative pain: A hospital based study. International Journal of Scientific Study. Dec 2014; 2(9):89-92.

11. Hamel KJ. Incidence of adhesions at repeat cesarean delivery. American Journal Of Obstetrics And Gynecology. 2007 May 31;196(5):e31-32.

12. Chattopadhyay S, Goswami S. Palonosetron versus ramosetron prophylaxis for control of postoperative nausea and vomiting after cesarean delivery under spinal anesthesiaThe Journal of Obstetrics and Gynecology of India. 2015 Feb 1; 65(1):28-33.

13. Rokade A, Patange R P,Javadekar D P, Vhaval V. Peritoneal Closure in Caesarean Section; A Step to Omit or to Continue? International Journal of Recent Trends in Science and Technology.2013; 7(1): 26-30. 